\title{
Comunicação
}

[Communication $]$

\section{Dosagem hormonal e avaliação testicular em cachorro-do-mato (Cerdocyun thous) utilizando diferentes protocolos anestésicos}

\author{
[Hormonal analyses and testicular evaluation in Cerdocyun thous using different \\ anesthetic protocols] \\ N.P. Souza, L.D'A. Guimarães, R.C.R. Paz
}

Faculdade de Agronomia - Medicina Veterinária e Zootecnia - UFMT - Cuiabá/MT

O cachorro-do-mato (Cerdocyon thous) é uma das seis espécies de canídeos brasileiros, que, originalmente, habitava praticamente todo o território nacional. Hoje, acredita-se que esteja extinto em grande parte do país, apesar de não constar na lista nacional das espécies da fauna brasileira ameaçada de extinção pelo IBAMA (Brasil, 2009). Este trabalho teve por objetivo avaliar a influência de diferentes protocolos anestésicos para procedimentos de eletroejaculação, biometria, citologia e ultrassonografia dos testículos e colheita de sangue para avaliação de testosterona em Cerdocyon thous, mantidos em cativeiro.

Foram utilizados três machos adultos mantidos no Zoológico da Universidade Federal de Mato Grosso, Cuiabá, MT. A colheita de sêmen, sangue e biometria testicular foi realizada nos meses de maio, junho, julho, outubro, novembro/2007 e janeiro/2008, totalizando seis colheitas. A citologia aspirativa por agulha fina (CAAF) dos testículos foi realizada durante o último procedimento anestésico, e a ultrassonografia no quarto procedimento anestésico.

Após jejum alimentar de 12 horas, foi realizada a contenção física dos animais com puçá, seguida de contenção química, com injeção intramuscular dos fármacos: tiletaminazolazepan $-7 \mathrm{mg} / \mathrm{kg}-$, cetamina e xilazina -12 e $1 \mathrm{mg} / \mathrm{kg}-$, cetamina, xilazina e atropina -12 , 1,0 e $0,04 \mathrm{mg} / \mathrm{kg}-$, cetamina e midazolam - 12 e $0,5 \mathrm{mg} / \mathrm{kg}-$, e cetamina e acepromazina $-12 \mathrm{e}$ $0,1 \mathrm{mg} / \mathrm{kg}$. O protocolo tiletamina-zolazepan foi utilizado na primeira e na última colheita.
A eletroejaculação foi realizada com aparelho Torjet-65® Eletrovet e probe com 17,0x1,8cm, contendo três tiras longitudinais em cobre de $8,8 \times 0,2 \mathrm{~cm}$. A probe foi introduzida no reto por aproximadamente $10 \mathrm{~cm}$, com as tiras longitudinais posicionadas ventralmente sob leve pressão. Ao pênis, exposto e devidamente lavado, foi acoplado um tubo coletor plástico graduado de $15 \mathrm{~mL}$. A série de eletrochoques seguiu o protocolo internacional utilizado em carnívoros selvagens (Howard, 1993).

Amostras de sangue foram obtidas por punção da veia jugular, utilizando-se o sistema Vacutainer Systems®. O material foi acondicionado em tubo estéril e mantido em isopor com gelo até o processamento. No laboratório, o sangue foi centrifugado a 300xg por 10 minutos, e o soro obtido armazenado em microtubos de $2 \mathrm{~mL}$, previamente identificados, os quais permaneceram em freezer $(-20 \mathrm{oC})$ até o momento das análises.

Para realização das dosagens hormonais de testosterona, foi utilizada a técnica de radioimunoensaio e um conjunto diagnóstico comercial Coat-A-Count DPC (Diagnostic Products Corporation, USA). Os procedimentos utilizados para as dosagens hormonais foram os mesmos especificados pelo fabricante, sendo que este conjunto diagnóstico utiliza como elemento traçador o hormônio marcado com ${ }^{125} \mathrm{I}$.

Os testículos direito e esquerdo foram avaliados quanto à consistência como rígido, flácido ou normal. A biometria testicular foi realizada com auxílio de paquímetro para determinação do

Recebido em 30 de março de 2011

Aceito em 20 de maio de 2011

E-mail: nelypsouza@hotmail.com 
volume testicular medindo-se o comprimento (c), a largura (1) e o volume (v), utilizando-se a fórmula: $\mathrm{v}=\mathrm{c}^{\mathrm{N}} \mathrm{1}^{2} \times 0,524$, em que o volume total é a somatória do volume dos testículos direito e esquerdo (Johnston et al., 1994).

A CAAF foi realizada após a limpeza dos testículos com solução físiológica e álcool iodado, os quais foram aspirados com agulha $25 \times 7$ e seringa de $10 \mathrm{~mL}$ descartáveis. Esfregaços foram realizados em lâminas de vidro e corados pelo método panótico rápido (Instant Prov, Newprov®). Um total de 200 células foi contado em microscópio óptico Nikon em aumento de $1000 \mathrm{x}$.

A ultrassonografia foi realizada com aparelho HONDA-VET 2000, modo-B dinâmico, transdutor convexo, na frequência de 7,0 MHz. Aos animais, submetidos à tricotomia da região escrotal, foi aplicado, sobre a pele, um gel de contato para transmissão ultrassônica (Carbogel®). As mensurações foram realizadas por meio de marcadores eletrônicos do próprio aparelho de ultrassonografia.

Para descrição dos resultados, foram usadas a média e os desvios-padrão. $\mathrm{O}$ test $\mathrm{t}$ foi $\mathrm{o}$ utilizado para avaliar as diferenças entre biometria testicular por ultrassom e por paquímetro (Statistic..., 1999).

Todos os protocolos anestésicos mostraram-se eficientes para manipulação segura dos animais durante a realização dos procedimentos propostos. A analgesia não foi avaliada de acordo com escala específica de dor, mas baseada em parâmetros clínicos como frequência cardíaca e frequência respiratória.

Durante o experimento, não foi possível a avaliação do sêmen em nenhuma das colheitas realizadas devido à contaminação de $100 \%$ do ejaculado por urina, o que indica que o método de eletroejaculação não foi eficiente para colheita de sêmen em cachorro-do-mato, independentemente da associação de fármacos utilizada para contenção. Trabalhos realizados em canídeos indicaram a retirada da urina da vesícula urinária por sonda antes do procedimento de eletroejaculação (Platz et al., 2001). Esse procedimento foi realizado em uma das colheitas do presente trabalho, no entanto houve eliminação de urina, em menor quantidade, porém suficiente para contaminar o sêmen obtido.

A concentração média de testosterona sérica obtida foi de $0,74 \pm 0,2 \mathrm{ng} / \mathrm{mL}$ (Tab. 1), indicando valores normais, com variação entre 0,02 e 3,46ng/mL, quando comparados aos encontrados na literatura para coiote (Canis latrans), variação de 0,44 a 3,3ng/mL (Minter e DeLiberto, 2008), e para cães domésticos variação de 1,31 a 2,02 (Martins et al., 2006). Os dados obtidos neste trabalho confirmam a sazonalidade reprodutiva desses animais, verificada pelo aumento na concentração sérica de testosterona nos meses de junho-julho.

Tabela 1. Concentrações séricas de testosterona (ng/mL) em cachorro-do-mato (Cerdocyon thous).

\begin{tabular}{llll}
\hline & Animal 1 & Animal 2 & Animal 3 \\
\hline Maio/07 & 0,02 & 0,61 & 0,22 \\
Junho/07 & 2,75 & 0,56 & 0,02 \\
Julho/07 & 1,99 & 1,61 & 3,46 \\
Outubro/07 & 0,03 & 0,08 & 0,75 \\
Novembro/07 & 0,30 & 0,02 & 0,50 \\
Janeiro/08 & 0,09 & 0,12 & 0,22 \\
\hline Média \pm DP & $0,86 \pm 1,1$ & $0,49 \pm 0,60$ & $0,86 \pm 1,2$
\end{tabular}

$\mathrm{DP}=$ desvio-padrão.

A CAAF, realizada para verificação da morfologia e porcentagem de células da série espermatogênica, e que se apresentou normal em todos os animais, indicou a presença de espermatozóides normais nos esfregaços (Tab. 2).

Ao exame ultrassonográfico, os testículos apresentaram-se com parênquima de ecotextura homogênea, com média ecogenicidade, túnica 
albugínea hiperecogênica e mediastino discreto e regular, sem sinais de anormalidades (Fig. 1), porém em menores dimensões que em cães domésticos de tamanho corporal semelhante (Hecht, 2008).

A palpação testicular indicou consistência normal. A média e o desvio-padrão do volume testicular mensurado nas seis colheitas foram de $3,8 \pm 1,5 \mathrm{~cm} 3$. A média e o desvio-padrão do volume testicular obtido por biometria ultrassonográfica e por paquímetro na quarta colheita foram, respectivamente, $1,1 \pm 0,3 \mathrm{e}$ $3,4 \pm 0,4 \mathrm{~cm} 3$ (Tab. 3).

Tabela 2. Tipos celulares (\%) encontrados em esfregaços de citologia aspirativa por agulha fina de testículos de cachorro-do-mato (Cerdocyon thous).

\begin{tabular}{llllc}
\hline Tipo Celular & Animal 1 & Animal 2 & Animal 3 & Média \pm DP \\
\hline Espermatogônia & 9,75 & 26,25 & 4,0 & $13,3 \pm 11,5$ \\
Espermatócitos I & 4,25 & 6,5 & 6,0 & $5,5 \pm 1,1$ \\
Espermatócitos II & 2,25 & 4,5 & 10,0 & $5,5 \pm 3,9$ \\
Espermátides iniciais & 8,25 & 10,25 & 20,0 & $12,8 \pm 6,2$ \\
Espermátides finais & 39,25 & 19,5 & 20,0 & $26,2 \pm 11,2$ \\
Espermatozóides & 11,25 & 12,5 & 20,0 & $14,5 \pm 4,7$ \\
Células de Sertoli & 25,0 & 20,5 & 20,0 & $21,8 \pm 2,7$ \\
\hline
\end{tabular}

DP = desvio-padrão.
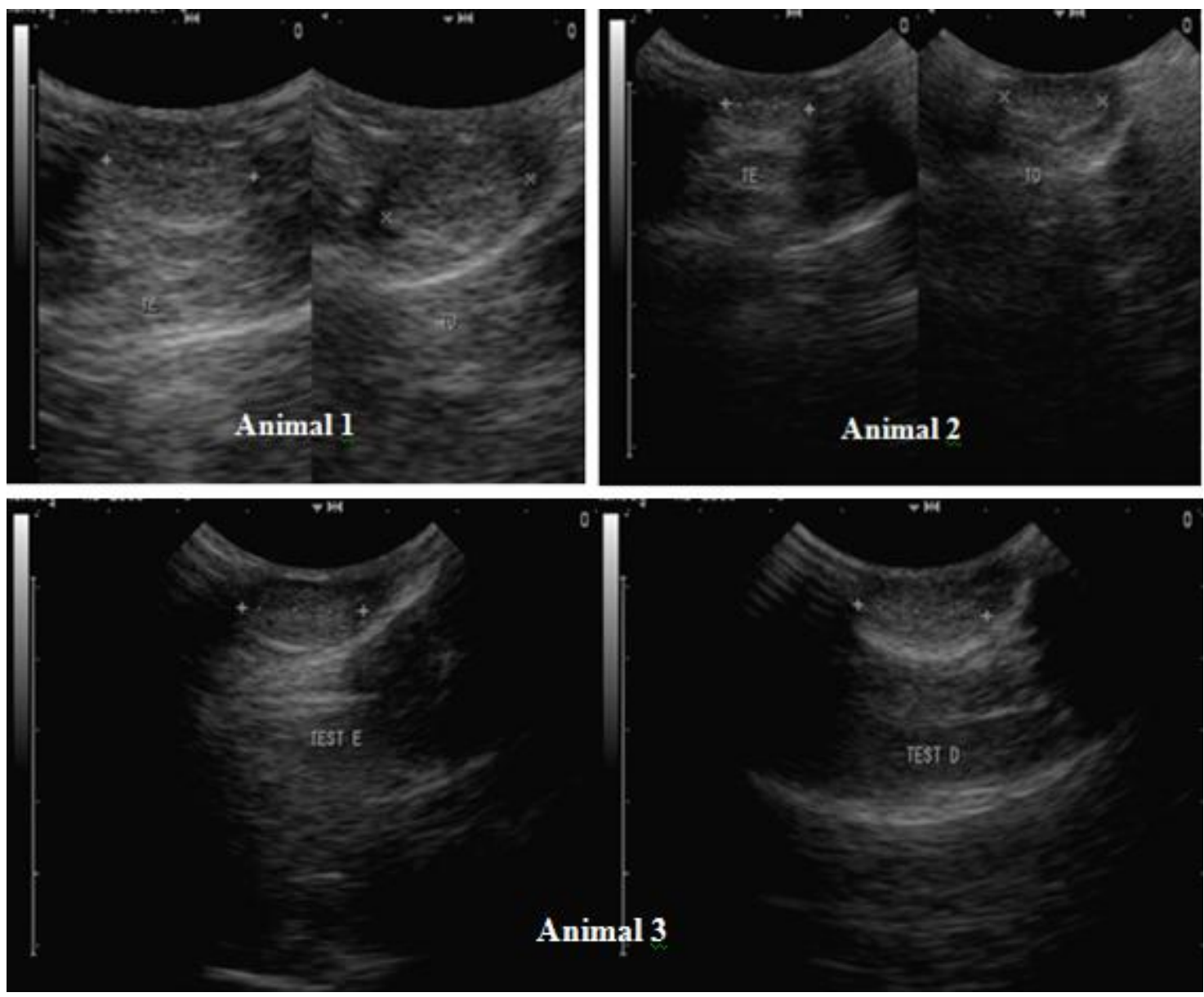

Figura 1. Ultrassonografia de testículos de cachorro-do-mato (Cerdocyon thous), Cuiabá/MT, 2008. 
Tabela 3. Volume testicular de cachorro-do-mato (Cerdocyon thous) obtido por biometria ultrassonográfica e paquímetro na quarta colheita e em todas as colheitas.

\begin{tabular}{|c|c|c|c|c|}
\hline & Animal 1 & Animal 2 & Animal 3 & Média $\pm \mathrm{DP}$ \\
\hline Biometria US $\left(\mathrm{cm}^{3}\right)\left(4^{\mathrm{a}}\right.$ colheita $)$ & 1,5 & 0,9 & 1,0 & $1,1 \pm 0,3 \mathrm{a}$ \\
\hline Biometria Paq. $\left(\mathrm{cm}^{3}\right)\left(4^{\mathrm{a}}\right.$ colheita $)$ & 3,6 & 2,9 & 3,6 & $3,4 \pm 0,4 b$ \\
\hline $\begin{array}{l}\text { Biometria Paq. }\left(\mathrm{cm}^{3}\right) \text { (Média de todas as } \\
\text { colheitas } \pm \mathrm{DP})\end{array}$ & $3,9 \pm 1,3$ & $3,8 \pm 0,9$ & $3,6 \pm 2,3$ & $3,8 \pm 1,5$ \\
\hline
\end{tabular}

Letras distintas na coluna indicam diferença entre valores $(\mathrm{P}<0,05)$; US = ultrassonografia; Paq = paquímetro; $\mathrm{DP}=$ desvio-padrão.

As médias da biometria testicular, obtidas por ultrassonografia e por paquímetro, foram diferentes $(\mathrm{P}<0,05)$, de onde se conclui que a ultrassonografia pode realizar biometria testicular com maior acurácia, por desprezar as medidas de pele e de tecido subcutâneo, o que não ocorre com o uso do paquímetro. Em estudo realizado em alpaca (Vicugna pacos), observou-se correlação entre mensuração ultrassonográfica dos testículos e peso testicular aferido após a castração. Essa correlação não foi verificada no presente trabalho pela aferição dos testículos com paquímetro, a qual superestimou o peso testicular, aspecto já descrito por Bott et al. (2008).

Palavras-chave: reprodução, canídeos selvagem, anestesia

\begin{abstract}
Tree Cerdocyon thous males received different anesthesia protocols: tiletamine-zolazepan (7mg/kg); ketamine-xylazine (12 and $1 \mathrm{mg} / \mathrm{kg})$; ketamine-xylazine-atropin $(12,1.0$ and $0.04 \mathrm{mg} / \mathrm{kg})$, ketaminemidazolam (12 and $0.5 \mathrm{mg} / \mathrm{kg})$ and ketamine-acepromazine (12 and $0.1 \mathrm{mg} / \mathrm{kg})$ for semen collection by electroejaculation, testosterone hormonal dosages, fine needle aspiration cytology (FNAC), testicular manual evaluation, biometry by caliper and ultrassonography (US). The ejaculates collected by electroejaculation showed urine contamination making impossible the semen evaluation. The $M \pm P D$ of serum testosterone was $0.74 \pm 0.2 \mathrm{ng} / \mathrm{mL}$. The cell types found in FNAC were: spermatogonia $13.3 \pm 11.5 \%$, primary spermatocytes $5.5 \pm 1.1 \%$, secondary spermatocytes $5.5 \pm 3.9 \%$, early spermatids $12.8 \pm 6.2 \%$, late spermatids $26.2 \pm 11.2 \%$, sperm $14.5 \pm 4.7 \%$ and Sertoli cells $21.8 \pm 2.7 \%$. Manual testicular evaluation showed normal consistency of testicles. The $M \pm P D$ of testicular biometry by caliper was $3.8 \pm 1.5 \mathrm{~cm}^{3}$ and by US was $1.1 \pm 0.3 \mathrm{~cm}^{3}$. The animals showed normal spermatogenesis with normal spermatozoa observed in FNAC and normal testicular US.
\end{abstract}

Keywords: reproduction, wildlife canides, anesthesia

\section{REFERÊNCIAS BIBLIOGRÁFICAS}

BOTT, N.I.; RODRIGUEZ, J.; SANDOVAL, S. et al. Relationship between testicular measurements using calipers or ultrassonography with testicular weight in alpacas (Vicugna pacos). Theriogenology, v.70, p.576-591, 2008.
BRASIL. Ministério do Meio Ambiente. Instrução Normativa MMA n 03 de 27 de maio de 2003. Lista nacional das espécies da fauna brasileira ameaçadas de extinção. Brasília, 2003. 19p. Disponível em: <www.mma.gov/port/sbt/fauna/index.cfm>. Acessado em: 20 ago. 2009. 
HECHT, S. Male reproductive tract. In: PENNINCK, D.; ANJOU, M. A. Atlas of Small Animal Ultrassonography. (Ed). Iowa: Blackwell Publishing, 2008. p.417-443.

HOWARD, J.G. Semen collection and analysis in carnivores. In: FOLWER, M.E. Zoo \& Wild Animal Medicine Current Therapy. 3.ed. Philadelphia: Saunders, 1993. p.390-399.

JOHNSTON, L. A., ARMSTRONG, D. L.; BROWN, J. L. Seasonal effects on seminal and endocrine traits in the captive snow leopard (Panthera uncia). J Rep Fert, v.102, p.229-236, 1994.

MARTINS, I.M.; SOUZA, F.F.; OBA, E. et al. The effect of season on semen testosterone concentration in dogs. Theriogenology, v.66, p.1603-1605, 2006.
MINTER, L.J.; DeLIBERTO, T.J. Seasonal variation in serum testosterone, volume testicular, and semen characteristics in coyote (Canis latrans). Theriogenology, v.69, p.946952, 2008

PLATZ, C.C; WADDELL, W.; SMITH, R. et al. Semen collection in wild canidae using electroejaculation. IN: LOSKUTOFF, N. M.; CRICHTON, E.G. (Eds). Proceedings of the first international symposium on assisted reproductive technology for the conservation and genetic management of wildlife, Henry Doorly Zoo, USA: Omaha, 2001. p.134-135.

STATISTIC analyses program, 99, 2.ed. Stat Soft Inc, 1999. 